\title{
Assessment of Serum Prostate Specific Antigen, Some Renal Indices and Uric Acid Levels in Subjects with Benign Prostatic Hyperplasia at Lokoja, Nigeria
}

Isaac Paul Emeje ${ }^{1}$, Nkiruka Rose Ukibe ${ }^{1 *}$, Charles Chinedum Onyenekwe ${ }^{1}$ and Nwakasi K Nnamah ${ }^{2}$

${ }^{1}$ Deparment of Medical Laboratory Science, College of Health Sciences, Nnamdi Azikiwe University, Nnewi Campus, Anambra State, Nigeria

${ }^{2}$ Deparment of Chemical Pathology, Faculty of Medicine, College of Health Sciences, Nnamdi Azikiwe University, Nnewi Campus, Anambra State, Nigeria

\begin{abstract}
Background: Prostate disorders (prostatitis, $\mathrm{BPH}$ and $\mathrm{Pca}$ ) can contribute to renal impairment. Benign prostatic hyperplasia (BPH) and renal impairment (RI) such as chronic kidney disease are important public health problems in older men. The present study aimed to assess serum levels of prostate specific antigen, urea, creatinine, protein and uric acids in subjects with BPH at Federal Medical Center, Lokoja, Kogi State, Nigeria. A population-based sample of one hundred and ten (110) men aged (51-70) years were conveniently recruited and divided into three groups designation $A=B P H$ with $R I,(n=35) B=B P H$ without $R I,(n=35)$ and $C=C o n t r o l,(n=40)$.
\end{abstract}

Methods: Blood samples were collected from all the participants and serum separated and stored at $-20^{\circ} \mathrm{C}$ until analyzed for prostate specific antigen using Enzyme Linked Immunosorbent Assay (ELISA) and colorimetric assay method for creatinine, urea, protein and uric acid. Data were analyzed using SPSS software application (version 17.0). Pearson correlation and Receiving Operating Characteristics of the groups were done.

Results: The result showed that urea and creatinine levels were significantly higher in BPH subjects with or without renal impairment when compared with controls ( $p<0.05$ respectively). Similarly, total prostate specific antigen (tPSA), free prostate specific antigen (fPSA), complex prostate specific antigen (cPSA) and percent free prostate specific antigen (\%fPSA) were significantly higher in $\mathrm{BPH}$ subjects with or without RI when compared with controls $(p<0.05$ respectively). Urea, creatinine and uric acid were significantly higher while total protein was significantly lower in BPH with RI when compared with $\mathrm{BPH}$ without $\mathrm{RI}(\mathrm{p}<0.05$ respectively).

Conclusion: The significantly higher urea, creatinine and uric acid levels in BPH subjects showed that BPH subjects with RI may have decrease excretion and accumulation of uric acid by the kidney suggesting possible risk of progression to CKD while BPH subjects without RI tends to be more prone to developing renal dysfunction. The significant correlation between \% fPSA, creatinine and urea shows an association between BPH and renal diseases. Using receiving operating characteristic $(R O C)$ curves to assess diagnostic performance of various parameters in various groups for the prediction of BPH with or without renal disease, there was evidence that fPSA and \%fPSA have higher predictive value in the diagnosis of BPH while uric acid, urea, creatinine and protein have higher predictive value in the diagnosis of renal disease. It is therefore, recommended that people with prostate disorders should be screened for renal diseases and vice versa.

Keywords: Benign prostatic hyperplasia; Prostate specific antigen; Renal indices; Uric acid; Chronic kidney disease; Nigeria

\section{Introduction}

Benign Prostatic Hyperplasia and Chronic Kidney Disease though a disease of aging male but can have familial inheritance [1]. This inheritance is because binding of Dihydrotestosterone to nuclear androgen receptors to signal growth of prostate gland is a function of genetic makeup of such individual. One possible risk factor for chronic kidney disease may be benign prostatic hyperplasia (BPH) [24]. $\mathrm{BPH}$ has been described as a common clinical syndrome in older men characterized by bladder outlet obstruction, lower urinary tract symptoms, and benign prostatic enlargement [5]. BPH is characterized by the non-malignant overgrowth of prostatic tissue surrounding the urethra, ultimately constricting the urethral opening giving rise to associated lower urinary tracts symptoms. In Nigeria, $25 \%$ of adult male Nigerians were reported to have BPH [6].

The late complication of $\mathrm{BPH}$ is Renal Impairment [7]. Renal Impairment is a serious condition associated with premature mortality, decreased quality of life and increased health-care expenditures. Untreated RI can result in end-stage renal disease that requires dialysis or kidney transplantation [7]. Men presented to urologist for $\mathrm{BPH}$ treatment show an average of $13.6 \%$ of renal failure in the United State [8]. The Rochester Epidemiology Project found a significant association between signs and symptoms of BPH and RI in their population-based sample of 467 white men [9]: there was a significant association between RI and BPH. Studies in Africa have shown that countries like Ghana, Nigeria, and Cameroon have similar prevalence of $25 \%$ of Benign Prostatic Hyperplasia in kidney disease [10]. In the United State of America, $13.6 \%$ of men with BPH have been reported to have chronic renal failure [11]. The impact of BPH and renal impairment on health should not be underestimated as it accounts for about $10 \%$ of hospital admission in Nigeria [6]. The most successful approach to detect BPH is the use of percent $\mathrm{fPSA}=f P S A \times 100 / \mathrm{tPSA}$, where $\mathrm{f}=$ free and $\mathrm{t}=$ total

*Corresponding author: Nkiruka Rose Ukibe, Department of Medical Laboratory Science, College of Health Sciences, Nnamdi Azikiwe University, Nnewi Campus, Anambra State, Nigeria, Tel: +2348062915510; E-mail: nr.ukibe@unizik.edu.ng/ ezinne4real2007@yahoo.com

Received September 06, 2017; Accepted November 29, 2017; Published December 06, 2017

Citation: Emeje IP, Ukibe NR, Onyenekwe CC, Nnamah NK (2017) Assessment of Serum Prostate Specific Antigen, Some Renal Indices and Uric Acid Levels in Subjects with Benign Prostatic Hyperplasia at Lokoja, Nigeria. J Bioanal Biomed 9: 256-262. doi:10.4172/1948-593X.1000189

Copyright: @ 2017 Emeje IP, et al. This is an open-access article distributed under the terms of the Creative Commons Attribution License, which permits unrestricted use, distribution, and reproduction in any medium, provided the original author and source are credited. 
Citation: Emeje IP, Ukibe NR, Onyenekwe CC, Nnamah NK (2017) Assessment of Serum Prostate Specific Antigen, Some Renal Indices and Uric Acid Levels in Subjects with Benign Prostatic Hyperplasia at Lokoja, Nigeria. J Bioanal Biomed 9: 256-262. doi:10.4172/1948-593X.1000189

which improve the clinical sensitivity and specificity of detecting BPH. Increase in \% fPSA is associated with BPH while an increase in the cPSA is associated with Prostate cancer [12]. Plasma creatinine $\geq 133$ umol/l (1.5 mgldl) defined renal impairment [13]. BPH left untreated causes stasis of bacteria leading to UTI, urinary bladder stones from crystallization of salts in residual urine, urinary retention progress to renal failure; urinalysis shows; Haematuria, Proteinuria as features of renal disease [6]. Blood urea greater than $8.3 \mathrm{mmol} / \mathrm{l}$ is associated with renal impairment though not specific [14]. Serum total protein has been reported to be decreased in prostate disorders and renal impairment [9]. The uric acid in prostate disorders (BPH \& PCa) and RI has been reported to be high due to decreased excretion of uric acid in renal diseases and prostate disorders [9].

Consultation for BPH constitutes a largest share of visit in urology departments worldwide with $6 \%$ of world population affected $(210$ million affected) [13]. Current screening procedures include clinical examination such as Digital Rectal Examination (DRE) and serum PSA measurement. Absolute PSA levels are difficult to interpret, as nonprostatic diseases can also increase the PSA levels [9]. The combination of DRE and PSA measurement would give a definitive diagnosis [9]. The present study thus aimed at evaluating the utility of serum levels of PSA (tPSA, fPSA, \%fPSA) urea, creatinine and uric acid, as a possible aid in the diagnosis of prostate disorders (BPH) and association of these disorders with renal impairment.

\section{Materials and Methods}

A total of one hundred and ten (110) adult male subjects aged (51-70) years were recruited for the study using convenient sampling technique. Seventy (70) participants from urology unit of Federal Medical Centre, Lokoja, Kogi State, Nigeria, who had undergone Transrectal ultra sonography (TRUS), Digital Rectal examination (DRE), and/or histologically confirmed and diagnosed were recruited. They were further grouped based on the results of PSA, biopsy, urea, creatinine and uric Acid obtained from urology clinic at Federal Medical Centre, Lokoja as group A: 35 subjects with BPH and renal impairment and group B: $35 \mathrm{BPH}$ subjects without renal impairment. The remaining forty (40) participants group C, were apparently healthy volunteers who were recruited among the hospital staff and used as control group.

\section{Methods}

Determination of Prostate Specific Antigen (PSA, Free PSA Assay) in human serum was done using enzyme immunoassay method (EIA) as described by [12] while complexed prostate specific Antigen (cPSA) was calculated mathematically by the formula cPSA=Total PSA (fPSA).

Determination of serum creatinine was done using colorimetric method as described by Jaffes method and using a cut off of plasma creatinine $\geq 133$ umol/l (1.5 mgldl) [15]. Blood urea was also measured using colorimetric method as described by [14] with cut off of Blood urea greater than $8.3 \mathrm{mmol} / \mathrm{l}$.

Determination of serum uric Acid was estimated using the colorimetric method as described by [16]. Also serum total protein was measured colorimetrically as described by the method of [9].

\section{Inclusion criteria}

Participants having BPH with or without renal impairment were included in the study. Apparently healthy subjects were included in the study as controls.

\section{Exclusion criteria}

Participants having Prostate cancer (Pca) with or without RI were excluded from the study. BPH Participants with or without RI who refused to give their consent, Pca participants with or without RI, control subjects with ailment related to BPH, Pca and RI such as subject with lung disease, tracheal disease, mumps were excluded from the study as control.

\section{Specimen collection}

Seven millilitres of venous blood were collected from each subject for the biochemical investigations. The blood was allowed to clot, separated and the serum stored at $-20^{\circ} \mathrm{C}$ till analysis of the biochemical parameters.

\section{Laboratory used for analysis}

All the laboratory analysis was performed at Clinical Chemistry Laboratory at Federal Medical Centre Lokoja, Kogi State, Nigeria.

\section{Statistical analysis}

The data obtained from the study was analyzed using SPSS version 17.0 statistical Package. The result was expressed as mean \pm SEM, statistical difference between groups was done using analysis of variance (ANOVA), Pearson's Correlation and Receivers Operating Characteristics [17]. The differences were considered significant when $\mathrm{P}<0.05$.

\section{Results}

Levels of PSA (tPSA, fPSA, cPSA, \%fPSA), urea creatinine, total protein and uric acid in $\mathrm{BPH}$ subjects with or without renal impairment

The mean value of age in the subjects: BPH with RI (62.9 years) and BPH without RI (59.2 years) were significantly higher than similar value in the controls (52.0 years) $(\mathrm{P}<0.05$ respectively).

The values of tPSA, fPSA, cPSA, \%fPSA, Urea, creatinine, total protein and Uric Acid are shown in Table 1. The values for BPH with RI are $14.76,4.66,10.10 \mathrm{ng} / \mathrm{ml}, 32.22 \%, 16.19 \mathrm{mmol} / \mathrm{l}, 583.29 \mathrm{umol} / \mathrm{l}, 62.94$ $\mathrm{g} / \mathrm{l}, 7.99 \mathrm{mg} / \mathrm{dl}$. The values for BPH without RI are $22.48,8.89,13.59$ $\mathrm{ng} / \mathrm{ml}, 42.71 \%, 7.68 \mathrm{mmol} / \mathrm{l}, 192.46 \mathrm{umol} / \mathrm{l}, 69.94 \mathrm{~g} / \mathrm{l}$, and $4.95 \mathrm{mg} / \mathrm{dl}$ The values for controls respectively are $2.27,0.05,2.20 \mathrm{ng} / \mathrm{ml}, 2.74 \%$, $4.80 \mathrm{mmol} / \mathrm{l}, 83.57 \mathrm{umol} / \mathrm{l}, 72.07 \mathrm{~g} / \mathrm{l}$ and $5.23 \mathrm{mg} / \mathrm{dl}$. The values tPSA, fPSA, cPSA, \%fPSA, urea, creatinine and uric acid were significantly higher while total protein was significantly lower in BPH subjects with or without RI when compared with controls ( $\mathrm{P}<0.05$ respectively).

Furthermore, the values of tPSA, fPSA, cPSA, \%fPSA in BPH subjects with RI $(14.76,4.66,10.10 \mathrm{ng} / \mathrm{ml}, 32.22 \%)$ were significantly lower when compared with the corresponding values in BPH subjects without RI $(22.48,8.89,13.59 \mathrm{ng} / \mathrm{ml}, 42.71 \%)(\mathrm{P}<0.05$ in each case $)$ however, urea, creatinine, and uric acid levels $(16.19 \mathrm{mmol} / \mathrm{l}, 583.29$ umol/l, $7.99 \mathrm{mg} / \mathrm{dl}$ ) in BPH subjects with RI were significantly higher when compared with the values in $\mathrm{BPH}$ without $\mathrm{RI}(7.68 \mathrm{mmol} / \mathrm{l}$, $192.46 \mathrm{umol} / \mathrm{l}, 4.95 \mathrm{mg} / \mathrm{dl}(\mathrm{P}<0.05$ respectively). The mean value of total protein was significantly lower in BPH with RI $(62.94 \mathrm{~g} / \mathrm{l})$ when compared with the value in $\mathrm{BPH}$ without $\mathrm{RI}(69.94 \mathrm{~g} / \mathrm{l})(\mathrm{P}<0.05)$.

Distribution of PSA (tPSA, fPSA, cPSA)(ng/ml), \%fPSA, urea $(\mathrm{mmol} / \mathrm{l})$, creatinine $(\mu \mathrm{mol} / \mathrm{l})$ and Uric Acid(mg/dl) in BPH subjects with or without RI and controls according to age ranges (51-60 and 61-70 years)

The mean values of (tPSA, fPSA, cPSA,\%fPSA, urea, creatinine and 
Citation: Emeje IP, Ukibe NR, Onyenekwe CC, Nnamah NK (2017) Assessment of Serum Prostate Specific Antigen, Some Renal Indices and Uric Acid Levels in Subjects with Benign Prostatic Hyperplasia at Lokoja, Nigeria. J Bioanal Biomed 9: 256-262. doi:10.4172/1948-593X.1000189

\begin{tabular}{|c|c|c|c|c|c|c|c|c|c|}
\hline Group & Age(years) & tPSA & fPSA & cPSA & \%fPSA & Urea & Creatinine & Total Protein & Uric Acid \\
\hline $\begin{array}{c}\text { Group A } \\
(n=35)\end{array}$ & $62.9 \pm 0.74$ & $14.76 \pm 0.26$ & $4.66 \pm 0.39$ & $10.10 \pm 0.35$ & $32.22 \pm 0.31$ & $16.19 \pm 0.99$ & $583.29 \pm 0.61$ & $62.94 \pm 0.83$ & $7.99 \pm 0.48$ \\
\hline $\begin{array}{c}\text { Group B } \\
(n=35)\end{array}$ & $59.2 \pm 0.73$ & $22.48 \pm 0.39$ & $8.89 \pm 0.52$ & $13.59 \pm 0.40$ & $42.71 \pm 0.56$ & $7.68 \pm 0.97$ & $192.46 \pm 0.50$ & $69.94 \pm 0.04$ & $4.95 \pm 0.33$ \\
\hline $\begin{array}{c}\text { Group C } \\
(n=40)\end{array}$ & $52.0 \pm 0.62$ & $2.27 \pm 0.15$ & $0.05 \pm 0.00$ & $2.20 \pm 0.15$ & $2.74 \pm 0.27$ & $4.80 \pm 0.20$ & $83.57 \pm 0.42$ & $72.07 \pm 0.80$ & $5.23 \pm 0.14$ \\
\hline F-value & 43.57 & 58.46 & 46.93 & 69.92 & 311.66 & 100.18 & 86.48 & 42.42 & 32.74 \\
\hline $\mathrm{P}$-value & $0.001^{*}$ & $0.001^{*}$ & $0.001^{*}$ & $0.001^{\star}$ & $0.001^{\star}$ & $0.001^{*}$ & $0.001^{*}$ & $0.001^{*}$ & $0.001^{*}$ \\
\hline AVB & $0.002^{*}$ & $0.019^{*}$ & $0.001^{*}$ & $0.001^{\star}$ & $0.001^{*}$ & $0.001^{*}$ & $0.001^{*}$ & $0.001^{*}$ & $0.001^{*}$ \\
\hline AVC & $0.001^{*}$ & $0.001^{*}$ & $0.001^{*}$ & $0.001^{*}$ & $0.001^{*}$ & $0.001^{*}$ & $0.001^{*}$ & $0.001^{*}$ & $0.001^{*}$ \\
\hline BVC & $0.001^{*}$ & $0.001^{*}$ & $0.001^{*}$ & $0.001^{*}$ & $0.001^{*}$ & $0.045^{* *}$ & $0.001^{*}$ & 0.056 & 0.539 \\
\hline
\end{tabular}

*values differ significantly from controls $(p<0.05)$,

$\mathrm{n}=$ sample size,

SEM = standard error of mean,

tPSA=Total Prostate Specific Antigen

fPSA $=$ Free Prostate Specific Antigen,

cPSA $=$ Complexed Prostate Specific Antigen

$\% \mathrm{fPSA}=$ Percent Free Prostate Specific Antigen

Table 1: Mean ( \pm SEM) PSA(tPSA, fPSA, cPSA)(ng/ml), \%fPSA, Urea(mmol/l), Creatinine( $\mu$ mol/l) and Uric acid(mg/dl) in group A(BPH with RI), B(BPH without RI) and $\mathrm{C}$ (Control) subjects.

\begin{tabular}{|c|c|c|c|c|c|c|c|c|c|}
\hline \multirow{2}{*}{$\begin{array}{c}\text { Group } \\
\text { Age range }\end{array}$} & \multicolumn{2}{|c|}{ BPH } & \multirow[t]{2}{*}{ P-value } & \multirow{2}{*}{$\begin{array}{l}\text { BPH with RI } \\
51-60(n=18)\end{array}$} & \multirow[b]{2}{*}{$51-70(n=17)$} & \multirow[t]{2}{*}{ P-value } & \multicolumn{2}{|c|}{ Control } & \multirow[t]{2}{*}{ P-value } \\
\hline & $51-60(n=18)$ & $61-70(n=17)$ & & & & & $51-60(n=20)$ & $61-70(n=20)$ & \\
\hline tPSA & $24.34 \pm 0.68$ & $20.51 \pm 0.87$ & 0.580 & $12.63 \pm 0.16$ & $17.01 \pm 0.35$ & 0.033 & $2.41 \pm 0.23$ & $2.10 \pm 0.19$ & 0.378 \\
\hline fPSA & $9.48 \pm 0.12$ & $8.26 \pm 0.77$ & 0.346 & $3.92 \pm 0.39$ & $5.44 \pm 0.64$ & 0.041 & $0.07 \pm 0.01$ & $0.04 \pm 0.00$ & 0.118 \\
\hline cPSA & $14.86 \pm 0.66$ & $12.24 \pm 0.12$ & 0.561 & $8.71 \pm 0.59$ & $11.57 \pm 0.83$ & 0.017 & $2.30 \pm 0.24$ & $2.09 \pm 0.19$ & 0.511 \\
\hline \%fPSA & $40.3 \pm 0.21$ & $43.7 \pm 0.09$ & 0.037 & $30.95 \pm 0.93$ & $37.98 \pm 1.31$ & 0.003 & $2.90 \pm 0.71$ & $1.90 \pm 0.31$ & 0.100 \\
\hline Urea & $7.35 \pm 0.10$ & $8.03 \pm 0.66$ & 0.731 & $15.31 \pm 0.11$ & $17.02 \pm 0.41$ & 0.014 & $5.02 \pm 0.37$ & $4.58 \pm 0.18$ & 0.296 \\
\hline Creatinine & $188.5 \pm 0.23$ & $196.2 \pm 0.32$ & 0.010 & $564.2 \pm 0.64$ & $601.3 \pm 0.99$ & 0.026 & $86.60 \pm 0.22$ & $80.55 \pm 0.33$ & 0.397 \\
\hline Uric Acid & $4.92 \pm 0.51$ & $5.00 \pm 0.21$ & 0.222 & $7.90 \pm 0.13$ & $9.50 \pm 0.24$ & 0.007 & $4.03 \pm 1.30$ & $4.70 \pm 1.20$ & 0.231 \\
\hline
\end{tabular}

Values differ significantly from controls $(\mathrm{P}<0.01)$,

$\mathrm{n}=$ sample size,

SEM = standard error of mean,

PSA $=$ Prostate Specific Antigen,

tPSA = Total Prostate Specific Antigen,

$\mathrm{fPSA}=$ Free Prostate Specific Antigen,

cPSA= Complexed Prostate Specific Antigen,

$\% \mathrm{fPSA}=$ Percent Free Prostate Specific Antigen

Table 2: Distribution of PSA (tPSA, fPSA, cPSA)(ng/ml), \%fPSA, Urea(mmol/l), Creatinine(umol/l) and Uric acid(mg/dl) in BPH withor without RI subjects and control according to age.

Uric Acid in control between 51-60 years were $(2.41,0.07,2.30,2.9 \%$, $5.02,86.6$ and 4.03 respectively) and between $61-70$ years $(2.10,0.04$, $2.09,1.9 \%, 4.58,80.55$ and 4.70 respectively). There was no significant difference in the age ranges among the control subjects $(\mathrm{P}>0.05)$.

However, in BPH subjects with RI, the mean values in 51-60 years $(12.63,3.92,8.71, \% 30.95,15.31,564.24,7.90)$ were significantly lower when compared with subjects between $61-70$ years $(17.01,5.44,11.57$, $37.98 \%, 17.02,601.20,9.50)(\mathrm{P}<0.05$ respectively $)$.

In $\mathrm{BPH}$ subjects without RI, the mean values \%fPSA and creatinine were significantly lower in subjects between $51-60$ years $(40.3 \% 188.53)$ when compare with subjects between $61-70$ years $(43.47 \%, 196.17)$ $(\mathrm{P}<0.05$ respectively). There was no significant difference in the values of other parameters between $51-60$ years $(24.34,9.48,14.86,7.35,4.92)$ and 61-70 years $(20.51,8.26,12.24,8.03$, and 5.0$)(\mathrm{P}>0.05$ respectively) (Table 2).

\section{Pearson's correlation study for BPH with or without Renal Impairment}

The results showed that \%fPSA was significantly negatively correlated with creatinine, urea and uric acid in $\mathrm{BPH}$ with $\mathrm{RI}(\mathrm{r}=-0.479$,$0.482,-0.422) \quad(\mathrm{P}<0.05$ respectively). Significant positive correlation was observed between creatinine and urea, creatinine and uric acid in
BPH subjects with RI ( $r=0.803, r=0.564)$ and in $\mathrm{BPH}$ subjects without $\mathrm{RI}(\mathrm{r}=0.067, \mathrm{r}=0.583)(\mathrm{P}<0.05$ respectively) while significant negative correlation existed between creatinine and protein in $\mathrm{BPH}$ subjects with RI $(-0.378, \mathrm{P}<0.05)$ and $\mathrm{BPH}$ without renal impairment $(\mathrm{r}=-0.349$, $\mathrm{P}<0.05)$.

\section{ROC'S/AUC'S}

ROCs are receivers operating characteristics, AUCs are area under the curve used to determine the diagnostic performance and association of different variables used in the assessment of BPH and RI (Figures 1-3).

\section{Discussion}

The present study aimed at evaluating the utility of serum levels of tPSA, fPSA, \%fPSA urea, creatinine and uric acid, as possible aid in the diagnosis of prostate disorder (BPH) and its association with renal impairments.

The study revealed significantly higher mean values of tPSA, PPSA, $\%$ fPSA, urea, creatinine and uric acid in all BPH subjects with or without renal impairment when compared with the values in control subjects. Additionally, free PSA and \%fPSA had a significantly higher diagnostic performance than CPSA and tPSA in the diagnosis of $\mathrm{BPH}$. Prostate is 
Citation: Emeje IP, Ukibe NR, Onyenekwe CC, Nnamah NK (2017) Assessment of Serum Prostate Specific Antigen, Some Renal Indices and Uric Acid Levels in Subjects with Benign Prostatic Hyperplasia at Lokoja, Nigeria. J Bioanal Biomed 9: 256-262. doi:10.4172/1948-593X.1000189

an important male reproductive system gland and its disorders such as benign prostatic hyperplasia (BPH) can affect men's quality of life and health [18]. Prostate specific antigen is a widely used tumor marker in the screening and management of BPH and prostate cancer. Several approaches are being introduced to improve the diagnostic accuracy of serum PSA testing. These approaches include assessing PSA and its forms. However, $4 \mathrm{ng} / \mathrm{ml}$ was chosen arbitrarily as a decision level

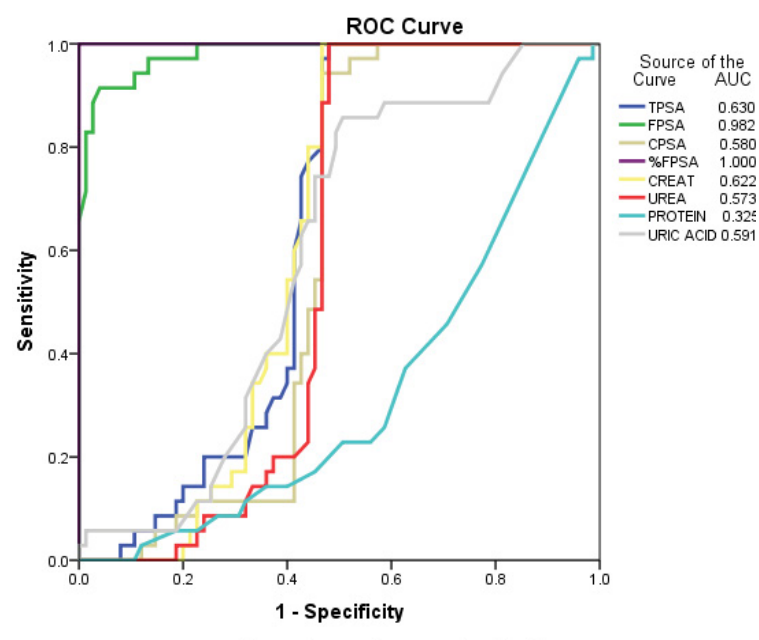

Diagonal segments are produced by ties.

Figure 1: ROC of tPSA, cPSA, fPSA, \%fPSA, Creatinine Urea, Protein and Uric Acid in BPH with Renal Impairment. The ROC of tPSA, cPSA, fPSA and \%fPSA, Creatinine Urea, Protein and Uric Acid in all the groups is given below:

Figure 1 showed the diagnostic performance of tPSA, fPSA, cPSA, \%fPSA, Creatinine Urea, Protein and Uric Acid for $\mathrm{BPH}$ with RI group. The results were tPSA (AUC.630), fPSA (AUC.982), cPSA (AUC.580) \%fPSA (AUC.1.000), Creatinine (AUC.622), Urea (AUC.573), Protein (AUC.325) and Uric acid (AUC.591). \%fPSA and fPSA had significantly higher diagnostic accuracy than tPSA in the prediction of BPH associated with RI. Creatinine, urea and uric acid had significantly higher diagnostic accuracy than protein in the prediction of RI associated with PD (BPH).

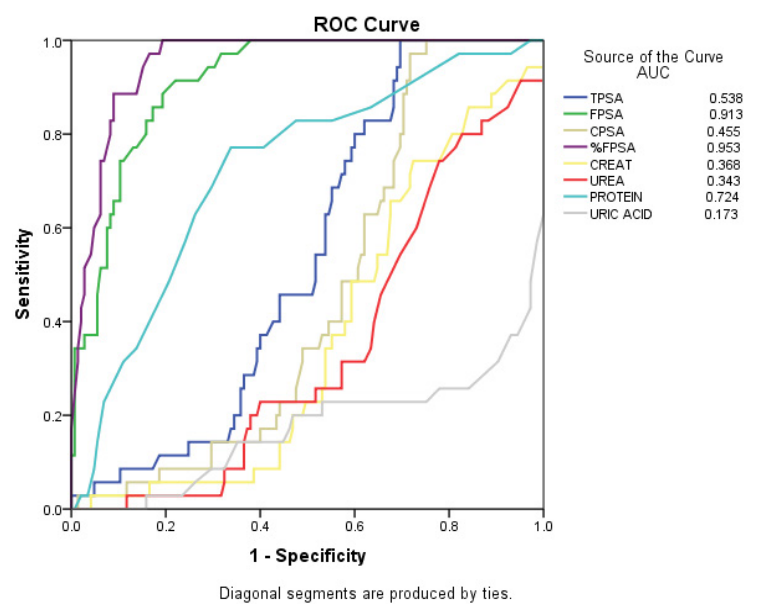

Figure 2: ROC of tPSA, cPSA, fPSA, \%fPSA, Creatinine Urea, Protein and Uric Acid in BPH without Renal Impairement. Figure 2 showed the diagnostic performance of tPSA, fPSA, cPSA, \%fPSA, Creatinine, Urea Protein and Uric Acid in BPH without RI subjects. The results were tPSA (AUC.538), fPSA (AUC.913) cPSA (AUC. 0.455) \%fPSA (AUC.953), Creatinine (AUC.368), Urea (AUC.343), Protein (AUC.0.724). and Uric Acid (AUC.173). \%fPSA and fPSA had a significantly higher diagnostic accuracy than IPSA in the prediction of $\mathrm{BPH}$. Protein had a significantly higher diagnostic accuracy than uric acid in the prediction of $\mathrm{BPH}$ without RI.

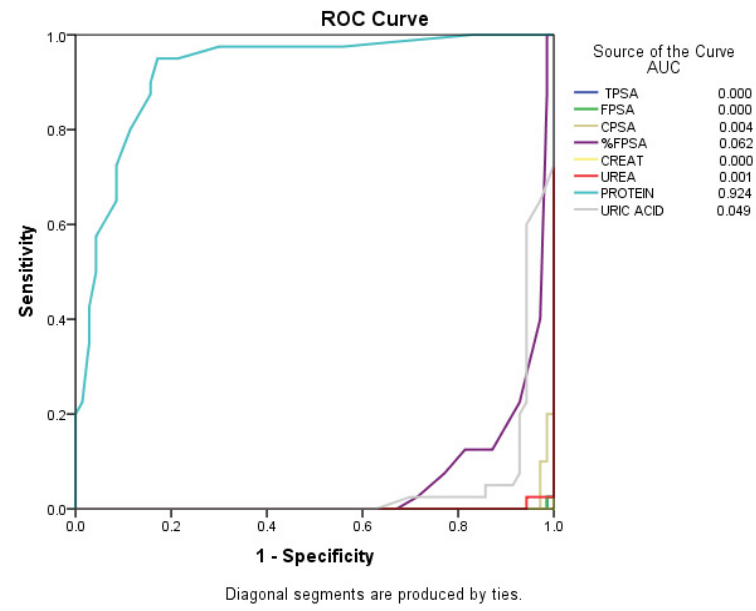

Figure 3: ROC of tPSA, cPSA, fPSA, \%fPSA, Creatinine Urea, Protein and Uric Acid in Control Subjects. Figure 3 showed the results of tPSA, fPSA, CPSA, $\% f P S A$, Creatinine, Urea Protein and Uric Acid in Control group. The results were tPSA (AUC.000), fPSA (AUC.000), cPSA (AUC.0.004) \%fPSA (AUC.062), Creatinine (AUC.000), urea (AUC.001) Protein (AUC. 0.924) and uric acid (AUC.049). \%fPSA showed higher predictive value than IPSA and fPSA. Protein had a statistically higher prediction value in control than urea and creatinine and uric acid.

\begin{tabular}{|c|c|c|c|c|}
\hline Group & \multicolumn{2}{|c|}{ BPH with R } & \multicolumn{2}{c|}{ BPH without R } \\
\hline Parameter & R & P & R & P \\
\hline \%fPSA vs. Creatinine & -0.479 & $0.005^{*}$ & -0.101 & 0.565 \\
\hline \%fPSA vs. Urea & -0.482 & $0.003^{*}$ & -0.054 & 0.756 \\
\hline \%fPSA vs. Uric Acid & -0.422 & $0.012^{*}$ & -0.096 & 0.585 \\
\hline Creatinine vs. Urea & 0.803 & $0.000^{*}$ & 0.677 & $0.000^{*}$ \\
\hline Creatinine vs. Protein & -0.378 & $0.005^{*}$ & -0.349 & $0.040^{*}$ \\
\hline Creatinine vs. Uric Acid & 0.564 & $0.000^{*}$ & 0.583 & $0.000^{*}$ \\
\hline
\end{tabular}

denotes significance level

Table 3: Pearson's Correlation Studies of BPH subjects with or without RI and Controls.

for biopsies in the clinical trial upon which the Federal Drug Agency (FDA) in 1994 based adding prostate cancer detection in man age 50 and over as an approved indication for the first commercially available PSA tests [19-21]. Recent study has shown that fPSA may be a useful tool in making therapeutic decisions and follow-up management in BPH patients [22]. Some of the biochemical parameters that were reported to be useful in the diagnosis of prostate cancer include free PSA to total PSA ratio [23] and serum to urinary PSA ratio [24]. It is evident in the current scenario, that there is a dearth of biochemical parameters for differential diagnosis of prostate disorders, paving way for the identification of newer ones. A tumor density of more than 0.15 as determined by serial testing of PSA for 2 years, distinguished BPH from prostatic carcinoma [25]. There is significant overlap between the serum PSA values of men with BPH and those of men with clinically localized prostate cancer. Reports shows that twenty-eight percent of men with histologically proven BPH have a serum PSA level greater than $4.0 \mathrm{ng} / \mathrm{mL}$ [26]. Serum PSA trends over time (PSA velocity), measurement of free versus complexed PSA, and PSA density may help to improve the specificity of PSA testing in men with BPH. Previous studies by Shirazi and colleaques also reported a significant correlation between age and serum PSA level as well as with prostate volume [18]. The authors further stated that a significant correlation existed between serum PSA level and prostate volume and therefore acute urinary retention $[18,27]$. These findings are conflicting considering the reports of Bhagya et al. [28]. 
The present study observed significant association between BPH and renal impairment. This was indicated by significantly higher urea, creatinine and uric acid levels which suggest some degrees of renal impairment and decrease excretion and accumulation of uric acid by the kidney in BPH with RI. Additionally, the significant correlation between \%fPSA, creatinine and urea also showed an association between BPH and renal diseases. These findings are inconformity with the findings of Barry et al. [8] that obstructive uropathy due to $\mathrm{BPH}$ ultimately leads to RI. The increased creatinine, urea and uric acid in $\mathrm{BPH}$ also are in conformity with Abioye et al. [29] and Akinsola et al. [30]. It was earlier reported that serum creatinine is associated with a high risk of prostate cancer; more so in advanced cases where the chances of survival were low [31]. The measurement of serum creatinine has been recommended in the initial evaluation of all patients with LUTS to exclude renal insufficiency caused by the presence of obstructive uropathy. However, in men with an elevated serum creatinine level, the etiology is rarely associated with acute or chronic urinary retention secondary to BPH. Obtaining a serum creatinine measurement may be an appropriate screen for renal disease unrelated to $\mathrm{BPH}$ [13].

Previous report however, showed that high serum creatinine cutoffs [up to $265 \mu \mathrm{mol} / \mathrm{L}(3.0 \mathrm{mg} / \mathrm{dL})$ ] can be used to identify cases of chronic kidney disease [32] and will miss less advanced disease. The 1994 Agency for Health Care Policy and Research created BPH clinical guidelines that recommended serum creatinine screening in men presenting with lower urinary tract symptoms, however a 2003 update discontinued the serum creatinine measurements [13]. Serum total protein has been reported to be decreased in PD and Renal Impairment [9]. The uric acid in prostate disorders (BPH \& PCa) and RI has been reported to be high due to decreased excretion of uric acid in renal diseases and prostate disorders [9]. These different approaches to BPH patients may lead to a significant amount of patients underdiagnosed for CKD. However, Blood urea greater than $8.3 \mathrm{mmol} / \mathrm{l}$ is associated with renal impairment though not specific [14]. Reshma and colleaques in their study have reported marked increases in the mean values of blood urea, $\mathrm{BUN}$ and $\mathrm{BUN} /$ creatinine ratio in prostate cancer and $\mathrm{BPH}$ compared to controls and thereby, concluded that BPH and cancer of prostate, the most common types of prostatic disorders in old age, are more prone to develop renal dysfunction [33]. This finding was supported by the earlier report which stated that many patients with kidney disease responded to surgical treatment of $\mathrm{BPH}$ [34]. It has also been reported in earlier studies, that $\mathrm{BPH}$ can progress into prostatic cancer [35]. Study has shown that prostate disorders have an association with end stage renal disorders (ESRD) and is also age related [36]. Late or end stage renal failure secondary to prostatic or bladder outflow obstruction should be amenable to prevention if cases are recognized early, however it still difficult to recognize which men with BPH are at risk of renal failure and need close investigation. For this reason we truly believe that is important to recognize specific variables that can be measured and are important bases or risk factors for the evaluation and treatment of BPH with or without renal impairments.

Despite the many possible causes of obstructive uropathy, in studies of elderly patients with acute renal failure, the most common cause among all patients was BPH $[37,38]$. Kumar et al. showed in their studies that acute renal failure in patients with obstructive uropathy was due to $\mathrm{BPH}(38 \%)$, neurogenic bladder (19\%), obstructive pyelonephritis (15\%). Although $\mathrm{BPH}$ is not a life-threatening condition, the impact of BPH on quality of life (QoL) can be significant and should not be underestimated [39]. According to the World Health Organization although the death rate attributable to $\mathrm{BPH}$ is negligible, the estimated DALY's (The sum of years of potential life lost due to premature mortality and the years of productive life lost due to disability) due to BHP is quite considerable. Most of the disability is probably due to severe clinical symptoms and/or late complications of BPH like CKD [7]. Benign prostate enlargement ends up in urinary obstruction causing degradation of renal function over time [13]. In previous retrospective study of 19 patients who were admitted to renal dialysis units for end-stage renal disease caused by $\mathrm{BPH}$, authors [40] raised awareness of $\mathrm{BPH}$ as a cause for $\mathrm{CKD}$ and suggested a more adequate screening of renal function in men with untreated LUTS.

The present study showed that in BPH with renal impairment, there were significantly higher tPSA, fPSA, \%fPSA, urea, creatinine and uric acid for both categories of age distribution (51-60 years and 6170 years). It was also noted that \% fPSA within the age range of 61-70 years was higher than that of 51-60 years of age. This age differences in the progression of diseases according to this study agreed with Cockett et al. [41] who reported that incidence rate increases from 3 cases per 1000 men at age 45-49 years to 38 cases per 1000 men by the age of 7579 years. The risk of BPH increases every year after the age of 40 . Some authors reported that $\mathrm{BPH}$ is present in $20 \%$ of men in their fifties, $60 \%$ of men in their sixties, and $70 \%$ of men by age 70 [42]. More recently a cross-sectional survey in Spain of 2,000 randomly sampled men who were 50 years or older showed a $2.4 \%$ prevalence of self-reported renal failure related to a prostate condition (9\% reported renal failure from any cause) $[13,43]$. Another study [44] showed that men presenting for prostate surgery had a $7.7 \%$ prevalence of renal failure compared to $3.7 \%$ prevalence in age matched men presenting for nonprostate surgery. Other statistical study revealed that men presented to urologist for $\mathrm{BPH}$ treatment showed an average of $13.6 \%$ of renal failure [45]. This proves that renal failure in men with advanced $\mathrm{BPH}$ does not only reflect older age.

Our correlation studies also showed positive significant correlation positive and negative correlations between parameters in BPH with RI. The correlation between \%fPSA and creatinine, \%fPSA and urea had a higher diagnostic performance used in the diagnosis of $\mathrm{BPH}$ associated with renal impairment. Additionally, using Receiving Operating Characteristics /Area under the curve derived from the trapezium drawn on the curves to determine the diagnostic performance and accuracy of the different variables used in the assessment of the BPH with or without RI. ROCs of BPH with renal impairment showed that \%fPSA had a significantly higher diagnostic accuracy than tPSA in the prediction of $\mathrm{BPH}$ associated with RI while $\mathrm{BPH}$ without RI also showed that fPSA and \%fPSA had a significantly higher diagnostic accuracy in the predication of BPH without renal impairment as free PSA is produced from transition zone. It was also observed that urea, creatinine, uric acid and fPSA had significantly higher diagnostic accuracy in the prediction of BPH with and without RI showing association between BPH and RI. Choi and colleagues previously, reported associations between IPSA, fPSA, age, and PV, the authors stated that the highest correlation was verified between PPSA and PV while the correlation coefficient between IPSA and PV was much lower. Also the ROC curves (for PV greater than 30,40 , and $50 \mathrm{~mL}$ ) showed that fPSA (area under the curve [AUC] outperformed tPSA in its ability to predict clinically significant PV enlargement [22].

Significantly a higher level of uric acid was observed in the present study among BPH subjects compared with controls. Uric acid is the end product of purine metabolism in humans due to loss of uricase enzyme activity during evolution [46]. It is produced primarily by the liver and intestine, and by other peripheral tissues such as muscles, endothelium and the kidneys. About two-thirds of uric acid is excreted by the kidney and the remaining one-third by the biliary system, hence uric acid 
Citation: Emeje IP, Ukibe NR, Onyenekwe CC, Nnamah NK (2017) Assessment of Serum Prostate Specific Antigen, Some Renal Indices and Uric Acid Levels in Subjects with Benign Prostatic Hyperplasia at Lokoja, Nigeria. J Bioanal Biomed 9: 256-262. doi:10.4172/1948-593X.1000189

accumulates in the presence of renal impairment. Hyperuricemia can result from overproduction, under-excretion of uric acid, or by both processes [47]. Genetic factors also influence serum uric acid level in different racial groups [48]. It also indirectly proved that hyperuricemia is a risk factor for CKD progression [49]. Amin and colleuques reported that serum uric acid is raised in patients with impaired renal function [50]. Marked hyperuricemia is known to cause acute renal failure via intrarenal crystal deposition [51]. However, recent studies suggest mild hyperuricemia may have vasoactive and proinflammatory effects independent of crystal formation [51]. Hyperuricemia is associated with renal disease, but it is usually considered a marker of renal dysfunction rather than a risk factor for progression. Recent studies have reported that mild hyperuricemia in normal rats induced by the uricase inhibitor, oxonic acid (OA), results in hypertension, intrarenal vascular disease, and renal injury. This led to the hypothesis that uric acid may be a true mediator of renal disease and progression [52]. Male gender is associated with a more rapid progression of renal disease independent of blood pressure, dietary protein intake, or serum lipid levels [52].

In conclusion, the significantly higher urea, creatinine and uric acid levels in $\mathrm{BPH}$ subjects revealed that $\mathrm{BPH}$ subjects with RI may have decrease excretion and accumulation of uric acid by the kidney suggesting possible risk of progression to $\mathrm{CKD}$ while $\mathrm{BPH}$ subjects without RI tends to be more prone to developing renal dysfunction. The significant correlation between \%fPSA, creatinine and urea showed an association between $\mathrm{BPH}$ and renal diseases. Using receiving operating characteristic (ROC) curves to assess diagnostic performance of various parameters in various groups for the prediction of BPH with or without renal disease, there was evidence that fPSA and \%fPSA have higher predictive value in the diagnosis of $\mathrm{BPH}$ while uric acid, urea, creatinine and protein have higher predictive value in the diagnosis of renal disease. It is therefore, recommended that men with prostate disorders should be screened for renal diseases and vice versa. Early screening for detection of $\mathrm{BPH}$ and renal dysfunction is also advocated for men at youthful age to avoid risk of developing BPH vis a vis renal impairment and its complications. Further longitudinal study using blood urea nitrogen/creatinine ratio and glomerular filtration rate is also necessary to ascertain a clearer picture of subjects with less advanced disease and may progress to CKD.

\section{Consent}

All authors hereby declare that all written informed consent was obtained from all the patients who participated in this study.

\section{Ethical Approval}

All author(s) hereby declare that all experiment and procedure have been examined and approved by the appropriate board of ethics committee of Federal Medical Centre Lokaja, Kogi State, Nigeria and research have therefore been performed in accordance with the standards laid down in the 1964 Declaration of Helsinki.

\section{References}

1. Abrams $\mathrm{P}$ (1999) Luts, BPH, BPE, BPO: A plea for the logical use of correct terms. Am J Practice 1: 65.

2. George NJ, O'Reilly PH, Barnard RJ, Blacklock NJ (1983) High pressure chronic retention. BMJ Clin Res Ed 286: 1780-1783.

3. Styles RA, Neal DE, Griffiths CJ, Ramsden PD (1988) Long-term monitoring of bladder pressure in chronic retention of urine: The relationship between detrusor activity and upper tract dilatation. J Urol 140: 330-334.

4. Comiter CV, Sullivan MP, Schacterle RS (1997) Urodynamic risk factors for renal dysfunction in men with obstructive and nonobstructive voiding dysfunction. J Urol 158: 181-185.
5. Emberton M, Andriole GL, de la Rosette J (2003) Benign prostatic hyperplasia A progressive disease of aging men Urology 61: 267-273.

6. Ezeanyika LUS, Ejike CECC, Obidoa O, Elom SO (2006) Prostate disorder in an apparently normal Nigerian Population 1: prevalence. Biochemistry 18: 127-132.

7. World Health organization (2000) The world Health report 2000: Health Systems; improving performance. World health Organization, Geneva.

8. Barry MJ, Fowler FJ (1992) Causes of Benign Prostatic hyperplasia. Am J Urology 4: 12-34.

9. Jacobsen SJ, Bergstralh EJ, Guess HA (1996) Predictive properties of Serum prostate specific antigen testing in a community-based setting. Am Archeology Inter Med 156: 2462-2468.

10. Arogundade FA, Sanusi AA, Hassan MO, Akinsola A (2011) The pattern, clinica characteristics and outcome of ESRD in Ile-Ife, Nigeria: Is there a change in trend? Afr Health Sci 11: 594-601.

11. Levi F, Lucchini $F(2003)$ recent trends in mortality from Benign prostatic hyperplasia. Prostate 56: 207-211.

12. Stowell LH, Sharman LE, Hamel K (1991) An enzyme-linked Immunosorbent Assay (ELISA) for prostate specific antigen. J Forensic Sci 50: 125-138.

13. Rule AD, Lieber MM (2005) is benign prostatic hyperplasia a risk factor for chronic renal failure. Eng J Urology 173: 691-696.

14. Sims J, Berthelot M (1995) Urea. In: Clinical Guide to Laboratory Test. (3 ${ }^{\text {rd }}$ edn), pp: $425-433$.

15. Jaffe M (1986) Creatinine. In: Clinical Guide to Laboratory Test. (3 ${ }^{\text {rd }}$ edn), pp: 562-571.

16. Paulson P, Mahler S (1991) Uric acid. In: Clinical Guide to Laboratory Test. (3rd edn), pp: 330-340.

17. Harry F, Steven CA (1995) Statistic concept and application. (1 ${ }^{\text {st }}$ edn), Cambridge University Press, UK, pp: 430-433.

18. Shirazi M, Ariafar A, Zeyghami S, Hosseini MM, Khezri, et al. (2014) Association of Diet With Prostate Specific Antigen and Prostate Volume. Nephrourol Mon 6: e19411.

19. Catalona WJ (1994) Comparison of Digital Rectal Examination and Serum Prostate Specific Antigen in the Early Detection of Prostate Cancer; Results of a Multicentre trial of 6,630 men. J Urology 151: 1283-1290.

20. Carter H, Coffey DS (1990) the prostate: an increasing medical problem Prostate 16: 039-048.

21. Thompson FM, Panter DK (2004) Prevalence of Prostate Cancer among Men with 2239-46. A Prostate Specific Antigen Level $<$ or $=4.0 \mathrm{ng} / \mathrm{ml}$. Eng J Med 350: $155-200$.

22. Choi H, Park JY, Shim JS, Kim JH (2013) Free Prostate-Specific Antigen Provides More Precise Data on Benign Prostate Volume Than Total ProstateSpecific Antigen in Korean Population. Int Neurourol J 17: 073-077.

23. Miele ME (2001) Percent free PSA as an additional measure in a prostate cancer screen. Clin Lab Sci 14: 102-107.

24. Stephen JM, Maxine AP (2007) Urology. In: Lowrence M, Tierney JR, Current Medical Diagnosis and Treatment. ( $46^{\text {th }}$ edn) McGrawHil, USA.

25. Polascik TJ, Oesterlingalan JE, Partin W (1999) Prostate specific antigen: decade of discovery-what we have learned and where we are going? J Urology 162: 293-306.

26. McConnell JD, Barry MJ, Bruskewitz RC (1994) Rockville, Md: Agency for Health Care Policy and Research; Benign prostatic hyperplasia: diagnosis and treatment. Clinical Practice Guideline No 8. AHCPR Publication 094-0582.

27. Herbert L (2004) Pathology, Epidermiology and Natural History of Benign Prostatic Hyperplasia. Rev Urol 9: 3-10.

28. Bhagya LA, Sampath KV, Rama D, Rama RJ, Harini (2012) Comparative study of biochemical markers in prostatitis, benign prostate hypertrophy and carcinoma of prostate with and without metastasis. International J Pharma Biosciences 2: 117-122.

29. Abioye-Kuteyi EA, Akinsola AE, (1999) Renal Disease: the need for community - based screening in rural Nigeria. Afr J Med Pract 6: 198-201. 
Citation: Emeje IP, Ukibe NR, Onyenekwe CC, Nnamah NK (2017) Assessment of Serum Prostate Specific Antigen, Some Renal Indices and Uric Acid Levels in Subjects with Benign Prostatic Hyperplasia at Lokoja, Nigeria. J Bioanal Biomed 9: 256-262. doi:10.4172/1948-593X.1000189

30. Akinsola O, Oguniyi JO, Ladipo GOA (1989) Disease causing chronic renal failure in Nigerians- a prospective study of 100 cases. Afr J Med Sci 18: 131137.

31. Weinstein SJ, Mackrain K, Virtamo J, Albanes D, et al. (2009) Serum creatinine and prostate cancer risk in a prospective study. Cancer Epidemiol Biomarkers Prev 18: 2643-2649.

32. Ireton RC, Krieger JN, Cardenas DD (1990) Bladder volume determination using a dedicated, portable ultrasound scanner. J Urol 143: 909-911.

33. Reshma KL, Sudha KL, Poornima A, Manjrekar L, Madan Gopal RL, et al. (2014) Evaluation of biochemical markers of renal dysfunction in prostate disorders and healthy controls. Inter J Biomed Adv Resear 5: 414-416

34. Rule AD, Jacobson DJ, Roberts RO, Girman CJ, McGree ME, et al. (2005) The association between benign prostatic hyperplasia and chronic kidney disease in community dwelling man. Kidney Inter 67: 2376-2382.

35. Hung SC, Lai SW, Tsai PY, Chen PC, Wu HC, et al. (2013) Synergistic interaction of benign prostatic hyperplasia and prostatitis on prostate cancer risk. Br J Cancer 108: 1778-1783.

36. Wada Y, Nakanishi J, Takahashi W, Kai N, Nakayama Y (2006) Mass screening for prostate cancer in patients with end-stage renal disease: a comparative study. BJU Int 98: 794-797.

37. Kumar R, Hill CM (1973) Acute renal failure in the elderly. Lancet 301: 90-91.

38. Tseng K, Kulkarni S, Humphreys EB, Carter BH, Mostwin JL, et al. (2014) Spinal Anesthesia does not impact prostate cancer recurrence in a cohort of men undergoing radical prostatectomy: An observational study. Reg Anesth Pain Med 39: 284-288.

39. McVary KT, Roehrbom CG, Avins AL, Barry MJ, Bruskewitz RC, et al. (2011) Update on AUA guidance on the management of Benign prostatic hyperplasia. J Urology.

40. Sacks SH, Aparicio SA (1989) Late renal failure due to prostatic outflow obstruction: a preventable disease. BMJ 298: 156-159.

41. Cockett AT, Barry MJ (1992) indications for treatment of Benign prostatic hyperplasia. The American urological Association Study. Cancer 70: 280-283.

42. Parsons J (2010) Benign Prostatic Hyperplasia and Male Lower Urinary Tract Symptoms: Epidemiology and Risk. Curr Bladder Dysfunct Rep 5: 212-218.

43. Hunter DJ, Berra-Unamuno A (1996) Prevalence of urinary symptoms and other urological conditions in Spanish men 50 years old or older. J Urol 155: 1965-1970.

44. Hill AM, Philpott N (1993) Prevalence and outcome of renal impairment at prostatectomy. Br J Urol 71: 464-468.

45. McConnell JD, Barry MJ (1994) Benign prostatic hyperplasia: diagnosis and treatment. Agency for Health Care Policy and Research. Clin Pract Guidel Quick Ref Guide Clin. pp: 1-17.

46. Álvarez-Lario B, Macarrón-Vicente J (2010) Uric acid and evolution. Rheumato 49: 2010-2015.

47. Fauci AS, Braunwald E, Kasper DL, Hauser SL, Longo DL, et al. (2008) editors Harrison's Principles of Internal Medicine. (1 $7^{\text {th }}$ edn), McGraw Hill, New York, USA, 353: 635-642.

48. Li S, Sanna S, Maschio A, Busonero F, Usala G, et al. (2007) The GLUT9 gene is associated with serum uric acid levels in Sardinia and Chianti cohorts. PLoS Genet 3: e194.

49. Zhang YF, He F, Ding HH, Dai W, Zhang Q, et al. (2014) Effect of uric-acidlowering therapy on progression of chronic kidney disease: A meta-analysis. $J$ Huazhong Univ Sci Technolog Med Sci 34: 476-481.

50. Amin-ul-Haq, Rashid M, Zahoor A, Jamil-ur-Rehman, Ghulam J (2010) Association of serum uric acid with blood urea and serum creatinine. Pak $J$ Physiol 6: 046-049.

51. Roncal CA, Mu W, Croker B, Reungiui S, Ouyang X, et al. (2006) Effect of elevated serum uric acid on cisplatin- induced acute renal failure. Am J Physiol Renal Physiol 292: 116-122.

52. Kang DH, Nakagawa T, Feng L, Watanabe S, Han L, et al. (2002) A role for uric acid in the progression of renal disease. J Am Soc Nephrol 13: 2888-2897. 